FEMP-2315

SPECIAL

UC-706

\title{
AUTOMATED CONTAINER TRANSPORTATION USING SELF-GUIDED VEHICLES: FERNALD SITE REQUIREMENTS
}

by

\section{F. Brack Hazen}

\author{
FERMCO \\ Fernald Environmental Restoration \\ Management Corporation
}

September 1993

PREPARED FOR THE

FERUAL ENMRONMENTAL MANAGEMENT PROJECT

FERLAN ENMROMMENTAL RESTORATION MANAGEMENT CORPORATION

P. O. BOX 398704

Cancinnan, OH10 $45239-8704$

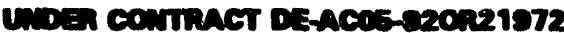

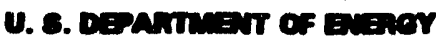

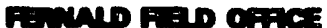


NOTICE FOR OTHER THAN ENVIRONMENTAL REPORTS (INTERNAL SPECIALS, SPECIALS, SUBCONTRACTOR, TOPICAL REPORTS):

THIS REPORT WAS PREPARED AS AN ACCOUNT OF WORK SPONSORED BY AN AGENCY OF THE UNITED STATES GOVERNMENT. NEITHER THE UNITED STATES GOVERNMENT OR ANY AGENCY THEREOF, NOR ANY OF THEIR EMPLOYEES, NOR ANY OF ITS CONTRACTORS, SUBCONTRACTORS NOR THEIR EMPLOYEES MAKES ANY WARRANTY, EXPRESS OR IMPI.IED, OR ASSUMES ANY LEGAL LIABILITY OR RESPONSIBILITY FOR THE ACCURACY, COMPLETENESS, OR USEFULNESS OF ANY INFORMATION, APPARATUS, PRODUCT, OR PROCESS DISCLOSED, OR REPRESENTS THAT ITS USE WOULD NOT INFRINGE PRIVATELY OWNED RIGHTS. REFERENCE HEREIN TO ANY SPECIFIC COMMERCIAL PRODUCT, PROCESS, OR SERVICE BY TRADE NAME, MANUFACTURER OR OTHERWISE, DOES NOT NECESSARILY CONSTITUTE OR IMPLY ITS ENDORSEMENT, RECOMMENDATION, OR FAVORING BY THE UNITED STATES GOVERNMENT OR ANY AGENCY THEREOF. THE VIEWS AND OPINIONS OF AUTHORS EXPRESSED HEREIN DO NOT NECESSARILY STATE OR REFLECT THOSE OF THE UNITED STATES GOVERNMENT OR ANY AGENCY THEREOF, OR FERNALD ENVIRONMENTAL RESTORATION MANAGEMENT CORPORATION, ITS AFFILIATES OR ITS PARENT COMPANIES.

DOE-FERMCO PRIME CONTRACT NO. IS DE-ACO5-920R21972. 
Table of Contents

$1.0 \quad$ Executive summary 1

2.0 Purpose 3

3.0 Introduction 4

3.1 The Fernald Site 5

3.2 Material handling 7

3.3 The factory view of remediation sites 10

3.4 Self Guided Vehicles 12

3.5 Resources for system development 14

4.0 Information management 16

4.1 Fernald's waste database- SWIFTS 17

4.2 Operations integration opportunities 18

-5.0 Proposal for the development of self guided vehicles 18

$\begin{array}{ll}5.1 \text { Motivation } & 19\end{array}$

5.2 Phase One: Human assist 20

5.3 Phase Two: Structured environments 21

5.4 Phase Three: Unstructured environments 21

5.5 Benefits of the final system 22

6.0 Fernald site requirements 22

6.1 Results of a previous materials handling study 23

6.3 Site transportation requirements - 24

6.4 Applications $\quad 26$

6.5 Safety approvals 28

6.6 Quality approvals 29

6.7 Site transport procedures and regulations 30

7.0 Research on the State of the Art for SGV's 32

$\begin{array}{lll}8.0 & \text { Conclusions } & 34\end{array}$ 
Table of Figures

1 The Fernald Site

2 Material handling equipment at the FEMP

3 An automated guided vehicle with lifting capacity

4 An automated guided pallet vehicle

5 Previous SRTC robots

6 Radiological survey of a truck

7 Technology tree for SGV development components 


\subsection{Executive summary}

A new opportunity to improve the safety and efficiency of environmental restoration operations, using robotics has emerged from advances in industry, academia, and government labs. SelfGuided Vehicles (SGV's) have recently been developed in industry and early systems have already demonstrated much, though not all, of the functionality necessary to support driverless transportation of waste within and between processing facilities. Improved materials databases are being developed by at least two DOE remediation sites, the Fernald Environmental Management Project (FEMP) in the State of Ohio and the Hanford Complex in the State of Washington. SGV's can be developed that take advantage of the information in these databases and yield improved dispatch, waste tracking, report and shipment documentation. In addition, they will reduce the radiation hazard to workers and the risk of damaging containers through accidental collision.

Many DOE remediation sites, including the FEMP, have millions of cubic yards of material that will be generated during cleanup activities. The material handling equipment and methods that have been sufficient for present operations will not be able to efficiently support anticipated increases in transport requirements. Currently, most material handling is done by operator driven fork lift, which is both inefficient and potentially dangerous to workers. Dispatching these activities is done manually, which generates a lot of paperwork but does not optimize system efficiency. Containers can get damaged as they are being moved, especially when they are large or extracted from tight spaces.

In order to surmount the escalating transport needs and problems with established methods, a plan to develop Self Guided Vehicles is presently being prepared. The project focusses on the development of a single SGV, centralized dispatch and tracking systems, and software simulations to demonstrate traffic management and operations dispatch. It will result in a vehicle that can lift an 8000 pound payload, which is the maximum weight of a filled pallet or B-25 box. Multiple SGV's will then be available to build fleets that can address a site's transport requirements. Applications that will be supported by the system will include container movements both within and between facilities, loading of trucks and rail cars, and the consolidation, shipment picking and access of containers in waste storage areas.

The safety and reliability of SGV's and mobile robots have already been demonstrated. Obstacle avoidance routines have been developed for moving and stationary objects that incorporate redundant sensor systems so that even if one sensor misses the object, the second or third level sensor will detect the obstacle and cause the vehicle to move around it. However, justifiable concerns remain concerning the safety of SGV's carrying heavy loads near people. Thus, the plan identifies three phases that will demonstrate progressively higher levels of safe automation. 
In Phase 1, a manually operated forklift will be modified to display dispatches from a central station, and a sensor based obstacle detection system will be included that can identify when a transported load or the vehicle is about to crash into an obstacle. In Phase 2, a vehicle will be purchased and modified to support autonomous navigation and container grappling in structured environments and for a limited range of applications. In Phase 3, the vehicle will be improved to support operation outdoors and in less structured environments. The full complement of proposed applications will be tested. Further integration between dispatching, database and vehicular operations will be accomplished.

Many advantages will result from the use of SGV's at remediation sites. Radiation exposure to vehicle drivers from the waste will be eliminated since there are no drivers. The likelihood of collisions will be reduced by previewing the path to be taken with the container and checking for any possible collisions against an accurate, sensor-updated model of the environment. They will also be able to access a specific drum in a close packed storage area, even if that means destacking and re-stacking multiple pallets. Multiple SGV's will be able to work in closer proximity with fewer traffic problems since their movement can be coordinated by a central control agent. Multiple shift operation seven days a week will be feasible. Permanent records of the activity will be recorded and timestamped on unalterable media when appropriate. Paperwork will be reduced and operational predictability will improve.

In this document, features of remediation sites that dictate the design of both the individual SGV's and the collective system of SGV's are presented, through the example of the site requirements at Fernald. Some concepts borrowed from the world of manufacturing are explained and then used to develop an integrated, holistic view of the remediation site as a pseudo-factory. Transportation methods at Fernald and anticipated growth in transport demand are analyzed. The new site-wide database under development at Fernald is presented so that advantageous and synergistic links between SGV's and information systems can be analyzed. Details of the SGV development proposed are submitted, and some results of a recently completed state of the art survey for SGV use in this application are also presented.

While adaptation of SGV's to environmental remediation sites will require some additional engineering and development, the project as proposed is both feasible and relevant to the material handling applications that will be encountered at DOE remediation sites. The development and use of SGV's can further advance, on all fronts, the mission to develop systems that are faster, safer, and more cost-effective, to the benefit of both Fernald and other DOE sites. 


\subsection{Purpose}

The Fernald Environmental Management Project (FEMP) is a Department of Energy (DOE) site located near Cincinnati Ohio. A former uranium foundry and mill consisting of over 100 structures, it is slated for dismantlement over the next decade. At present, the extent and nature of the contamination on site is being assessed and planning for final clean-up is beginning as some reduced scale remediation projects are implemented.

Fernald is the first of many large DOE sites that will undergo remediation. The problems encountered and solved at Fernald will be similar to those that other sites, such as Hanford and Oak Ridge, will experience. However, the radiological hazard is significantly less than at these other facilities because only low enrichment and depleted Uranium were produced.

One current activity at Fernald is the identification and development of technologies that will allow the remediation to proceed safer, more efficiently, and at the lowest possible cost to taxpayers. The Office of Technology Development (OTD) is the DOE office that is charged with coordinating these efforts amongst DOE sites and national laboratories and funding them. The Robotics Technology Development Program (RTDP) is the part of the OTD responsible for the development of robots and related systems that can help in the daunting task of remediating the DOE sites.

This report is intended to discuss the need for advanced material handling equipment at Fernald and present a proposal for the development of Self Guided Vehicles (SGV's) that can fill this need. Site requirements are identified for the procurement, deployment, and operation of these vehicles. A State of the Art report is being completed at University of Cincinnati and some preliminary findings are included to support the feasibility of SGV's for this application.

RTDP has supported the research into SGV's in order to determine the functional requirements that site characteristics will dictate and technical feasibility, before deciding whether to commit to a full scale development effort. Any further work will be managed under RTDP's Mixed Waste Operations (MWO) coordination area. SGV's would fit in well with the MWO mission to develop robots and automated systems to help in the processing and transportation of mixed waste both inside and between facilities. A preliminary plan has been created to develop SGV's using the resources available through the RTDP. 


\subsection{Introduction}

At a functional level, the project envisioned will ultimately develop autonomously navigating fork lift trucks that can identify, pick up, transport, and deposit individual containers or pallets. This fleet will be dispatched and coordinated automatically from a central computer workstation. The forklifts, or SGV's, will represent a considerable improvement over presently available Automated Guided Vehicles (AGV's). While yielding similar cost savings, SGV's offer enhanced operational efficiency and predictability.

Most of the major pieces required to assemble a SGV system have previously been demonstrated. AGV's have proven themselves to be safe and useful in factory settings. What remains to be done is to integrate these pieces into a cost effective system employing the latest technologies, for the safe relocation of containers in unstructured environments with a minimum of human involvement. The product will be a system that is able to help reduce operator exposure and address the growing container transportation needs at sites like Fernald.

In order to increase the acceptance of the final SGV system, a phased plan has been proposed that will allow for the gradual automation of activities and their demonstration prior to further development. The specter of automatons hoisting and transporting very heavy loads causes discomfort and safety concerns for some people. The burden of proof will remain on the developers to show that self-navigating systems can be developed that are safe to workers, facilities, and the environment. With this capacity satisfactorily demonstrated, the other benefits of SGV's will be readily apparent and should lead to a strong demand for these systems in the field.

The remainder of this section is devoted to giving a brief overview of the Fernald site, why it needs material handling equipment, and a general description of Self Guided Vehicles. Resources for system development are also introduced. One of the main advantages of SGV's are their capacity to be coordinated and controlled by a central, computerized agent that can respond to real-time transportation requirements by dispatching vehicles in a near-optimal manner.

A new sitewide material database is under development at Fernald and it is presented in Section 4. It will be able to provide the information foundation, framework for data organization and validation methods needed for automated dispatch. The proposal for the development of SGV's by the RTDP, as it exists today, is presented in section 5. The methods being used today to transport waste will need to be modified to cope with anticipated volume increases as remediation begins in earnest. However, the same elements will be required and these are discussed in section 6. Applications and scenarios for SGV use are also presented, as well as some of the approvals required for its operation on site. A discussion of the requirements for acceptance of new systems on site is included there. Some results of the State of the Art study that was conducted into the component technologies of SGV's are presented in Section 7, and are followed by concluding remarks. 


\subsection{The Fernald Site}

The Fernald Environmental Restoration Project (FEMP) is a government owned, contractor operated facility that refined, smelted, and machined high quality uranium metal for the DOE for over thirty years. The 136 acre production area is situated on 1050 acres of land 18 miles northwest of Cincinnati, Ohio. In 1989 production ceased and Fernald's mission changed to one of site remediation and waste management. It is presently being managed by FERMCO, wholly owned subsidiary of Fluor Daniel. A map of the site can be found in Figure 1.

During production operations much of the site became contaminated with uranium and its daughter products. Other hazardous materials such as heavy metals and Volatile Organic Compounds (VOC's) were also used. Several football field-sized pits have been filled to depths of up to thirty feet with production wastes. The buildings, process equipment within them, and some of the surrounding soil have been found to have these contaminants.

The U.S. Environmental Protection Agency placed the FEMP on the National Priorities List (NPL), along with the other 'superfund' sites, in 1989. Compared to other DOE sites, radiation levels at Fernald are quite low though the total amount of radioactively contaminated material is fairly high. Besides being the first DOE site to undergo complete shutdown and remediation, Fernald will be a proving ground for technologies that will subsequently be used to tackle even larger challenges at other DOE sites.

As an NPL site, Fernald must follow the remediation objectives laid out in the Comprehensive Environmental Response Compensation and Liability Act (CERCLA) as amended. The CERCLA blueprint for site remediation investigation and emphasizes thorough planning over several years prior to the actual clean up. It also suggests subdividing a cleanup site into Operable Units (OU's), grouping by commonality of contaminate, location, or physical form.

The Fernald site has five operable units, FERMCO's title for the groups that manage specific OU's. CRU 1 is responsible for engineering and project management for the cleanup of the large waste pits. CRU 2 covers other landfills and waste disposal areas on site. CRU 3 has responsibility for the largest and most complex job, the Decontamination and Dismantlement (D $\&$ D) of all contaminated process buildings and the equipment within them. CRU 4 will direct remediation of the three filled waste silos. CRU 5 covers the groundwater and soils remediation. Most of the actual design, construction, and remediation activities will be performed by subcontractors. 


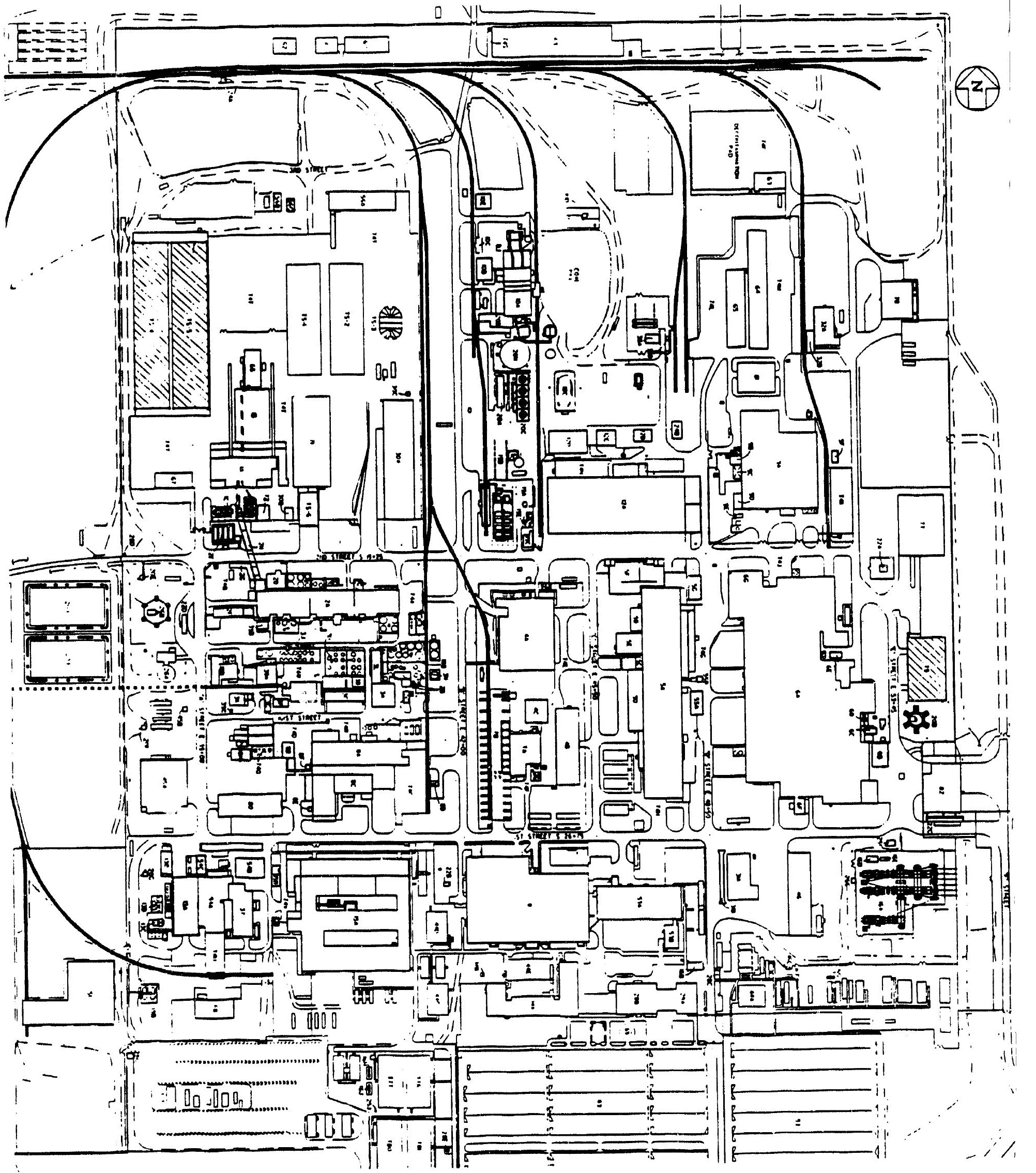

Figure 1- The Fernald site. 
Other groups working at Fernald assist in the CRU's activities. The Remedial Support Organization (RSO) provides much of the labor and line management required to carry out the CRU's plans. Its scope includes materials management, wage employees, analytical laboratory services, facilities management operations, maintenance, utilities, and quality control. On-site transportation is managed by the RSO operations division. Waste storage, shipping, and logistics

are addressed by RSO's materials management group. Both of these groups will need to be involved in the planning and development of the SGV project.

Under CERCLA, a Remedial Investigation (RI) is first conducted to determine the extent and level of contamination. Identified hazards that pose an immediate or impending threat to health or the environment are slated for Removal Action (RA), in which particularly acute problems can be remedied on an accelerated schedule. After completion of the Feasibility Study (FS) follows, in which different remediation alternatives are studied in order to identify the quickest, lowest cost and safest strategy. The proposed plan is then prepared, identifing the preferred remedial alternative. After the public comment period, a revised proposed plan may need to be issued. The final selected remedial alternative is documented in the Record of Decision (ROD). After the ROD is signed by EPA, DOE and the State (if it is a party) and made available to the public, remedial action can commence.

The long timetable both helps and hinders new technology developments such as the proposed SGV system. Through early demonstrations, new systems can be proven and included in future plans. However, since so much is unknown at present about the eventual course of the clean-up activities, including how clean the site should be rendered, it is difficult to predict the exact situations that the systems will be operating under.

\subsection{Material handling at the FEMP}

The FEMP, and many other DOE remediation sites, have an enormous amount of material that will be generated during the course of the cleanup artivities. Volume and weight estimates for total amount of waste at the Fernald site are found in Section 7.1. This material will have to be treated, containerized, transported to various locations on site, stored on a temporary basis and then shipped off site. Presently, materials handling is done by manually driven fork lift trucks. This exposes personnel to radiation and is inefficient. The fork lifts are dispatched to a particular job without considering the system-wide constraints of time, manpower, and efficiency. Loads can be difficult to negotiate in cramped aisles, leading to the potential for damaged or breached containers.

During remediation, larger, more unwieldy containers will be used. The volume of waste movements may outstrip the ability of personnel to track or dispatch them using today's methods. The procedures that have been used for container relocation have required a paper trail. Receipts and authorizations for container transportation are provided in written form. After the containers have been moved, databases must be updated manually, also. SGV's linked to a system-wide, data driven controller can address many of these difficulties, as will be presented in section 5.1 . 

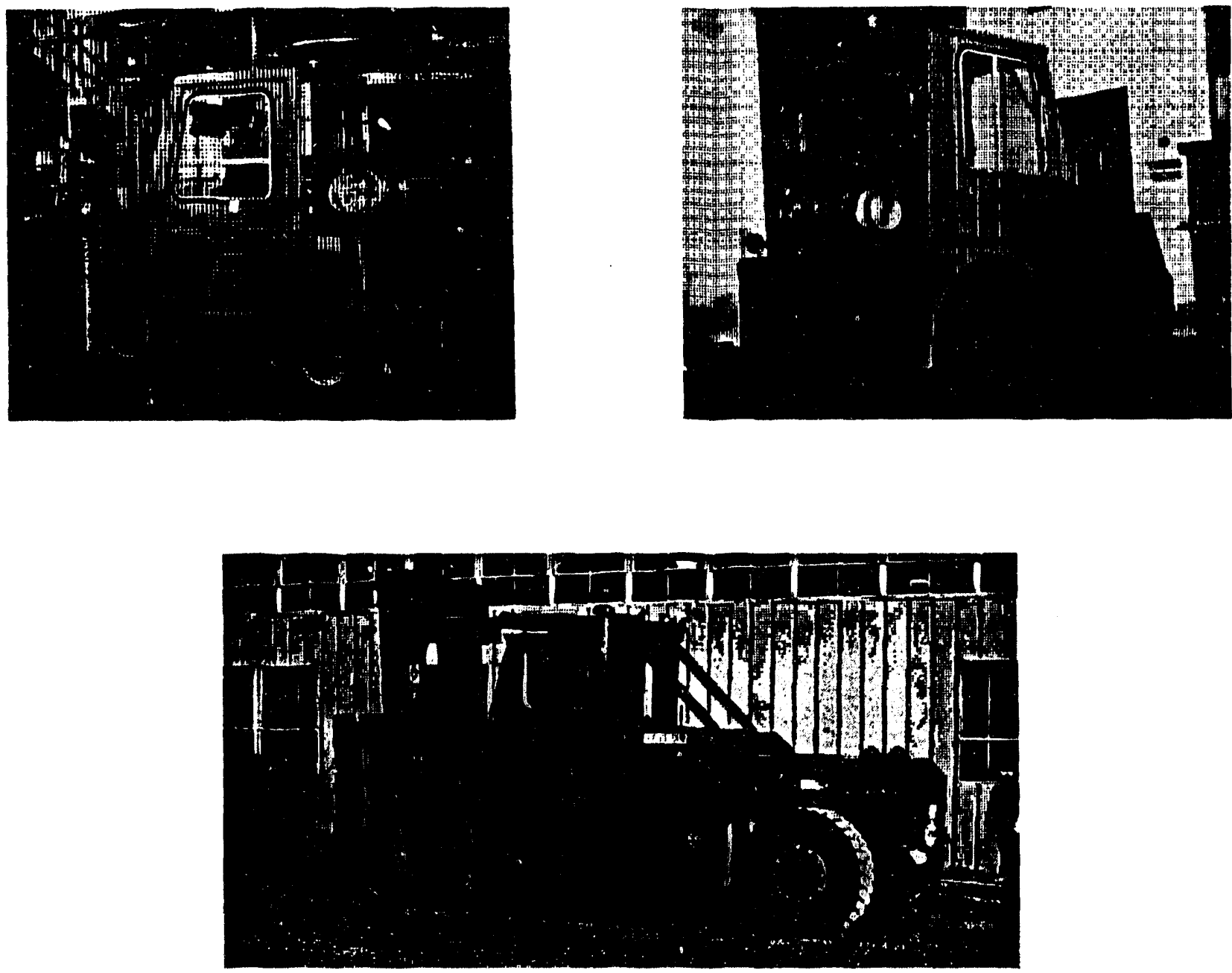

Figure 2- Material Handling equipment at the FEMP.

Clockwise from upper right, standard, tugger, and heavy duty trucks are shown.

Three types of material handling systems currently used on site are shown in Figure 2. Standard fork lifts are used to move anything from a single drum to a full pallet or a single B-25 box. Transporting a single drum requires a pallet underneath because they have no grappling capacity for drums. This works well, but at the cost of additional time to secure the load, that could potentially be avoided. Large scale Taylor forklifts are used to move very heavy loads and deposit them onto trucks for shipment. A need for this type of truck will remain because the new SGV system will not have that high a payload capacity. They could, however, benefit from automated dispatch. The final type of vehicle used is a tugger that pulls along a train of flat carts. This is an efficient mode of transportation when many objects of the same type are hauled. 
Until recently, drums have been the most popular container, in 55, 85 and 110 gallon sizes, with the 55 gallon size prevalent. However, they are difficult to transport individually. Multiple drums can be transported on pallets but only after they have been banded together and to the pallet to prevent them from tipping in transit. Also, drums do not promote good packing efficiency. For these reasons, larger B-25 boxes and ISO intermodal trailers have been used more recently. The B-25 boxes are also called '6-packs' because their size accommodates six 55 gallon drums. They are approximately $4 \mathrm{ft}$ high by $4 \mathrm{ft}$. deep and $5 \mathrm{ft}$. long and have receptacles underneath for easy lifting by a fork truck. The maximum allowable loading of B-25 boxes, per FERMCO Standard Operating Procedures (SOP), has been set at 8,000 pounds. ISO containers, standardized by and named for the International Shipping Organization, are the typical 'Sea-Land' intermodal trailers, and their dimensions are approximately $8.5 \mathrm{ft}$. high, 8 $\mathrm{ft}$. wide and $20 \mathrm{ft}$. long.

Radiological considerations dictate many present transportation procedures and will affect the design of the SGV system. When material is transported across contamination level zone boundaries, the vehicle and container exterior must be frisked for contamination before being allowed to pass. This is to insure the integrity of the rad boundaries between high radiation areas, contamination areas, radiation areas, etcetera. Using the centralized dispatch and control of SGV's, a slightly different approach could potentially speed up this process. One or more vehicles could be dedicated to each contamination zone. They woulc coordinate to efficiently transfer loads at the boundaries, with only the containers themselves being surveyed. For a limited number of container shapes and sizes, this could be readily automated as part of the SGV's supporting system, much more easily than for a whole vehicle.

Approximately $\mathbf{4 0}$ drivers now drive a fleet of 60 trucks, 40 of which are standard fork lifts. One quarter of the drivers are 'floaters' that can be flexibly deployed to particular sites as required. The other three quarters are assigned to specific buildings or areas and thus cannot respond as flexibly to real time requirements. For drivers working in contamination areas, three work hours are lost donning and doffing protective clothing at each of the four breaks in an eight hour shift. For these reasons, overall productivity suffers and, in some areas, is as low as $40 \%$ by some accounts.

The nature, mix, and volume of materials, pickup and delivery points, and container styles will be changing as the site is transformed from a sizable uranium factory to a construction site. Presently, waste containers are being moved from outside to inside storage, or they are being loaded into trucks and shipped offsite. Some containers are transported for overpacking, in which a damaged container is placed in a larger one. Deliveries of various supply materials are transported by fork lift or tugger.

When a container is identified as rusty and in need of overpacking, it must be retrieved from its storage location. This usually involves $\lambda$ fork lift and can be time consuming if the pallet holding the container is not at the end of an aisle. This is because rows of pallets are formed by starting at the outside walls of a facility area and successively stacking pallets towards the building center aisle. 
This way, vehicles do not enter the aisles between rows of pallets, so they can be made narrower and the storage area can hold more containers. Similarly, when samples need to be taken from specific drums, all pallets in the way of the one housing the drum of interest must be de-stacked and re-stacked starting from the center aisle. Some storage area aisles have ten or more pallets stacked four high so up to 39 pallets might have to be removed to get at a single drum.

Construction materials and boxes of slightly contaminated dirt are being moved around the site also, and the volume of this type of shipment will be increasing as remediation gets underway. Increasing numbers of rail cars as well as trailer trucks will need to be loaded for off-site shipment to disposal areas in order to match the increasing waste volumes from remediation activities. Some storage areas will experience tremendous turnover of stock as old containers are shipped out and new ones are generated. This will put increasing demands on the materials handling systems to consolidate storage areas that become fragmented and to rotate inventory so that old containers do not languish.

\subsection{The factory view of remediation sites}

Often it is possible to improve efficiency and throughput by systems analysis, modelling, and simulation. These tools can lead to a set of rules that are applied to the system control so that a particular weighted set of goal conditions (least cost, shortest route, etc.) can be maximized. For instance, in factories, this method of abstraction starts with viewing the whole factory as an interrelated system operating on raw materials from the incoming material loading dock to produce units outbound at the shipping area. Remediation sites can be viewed as a factory of sorts, in which the locations of 'workstations', and indeed the whole 'plant' layout, is constantly shifting.

The field of Operations Research has been dedicated to this type of industrial optimization and has developed many insightful analysis tools. Systems optimization can be applied to a fleet of SGV's at a remediation site like Fernald, with great benefits in utilization and efficiency. This section explores.one particular systems tool as an example of how integration of vehicles under a combination of central and distributed control can positively impact Fernald operations.

The popular and successful 'Just-In-Time' (JIT) manufacturing approach uses the systems level vantage point to identify bottlenecks in manufacturing processes and correct them. It focusses on material flow patterns and seeks to reduce the time that material has to wait before being processed at any workstation. The ultimate goal is to have only one widget waiting to be processed at any workstation. The series of widgets awaiting processing at each of the stations required to process it from a raw material to finished product then form a chain. 
The JIT chain allows the supply from the factory to match the demand from the market. Theoretically, when a customer 'pulls' an item off the shelf, that action draws another product from the shipping dock of the factory, and the 'pull' is propagated all the way back to the supplies of raw materials necessary to make it. In practice JIT may require some holding queues larger than one unit of size, so that certain operations, like shipping, can take advantage of economies of scale.

Fernald will be able to benefit from a JIT approach to remediation activities. There is still considerable uncertainty concerning the number and type of treatment and storage facilities that will exist on site in the future. However, a remediation effort has several stages regardless of the technology involved. The stages are retrieval, decontamination, waste minimization, stabilization, interim storage, and shipment to a disposal site.

Retrieval is the process in which the waste material is removed from its present location and transported to the treatment facility. Once in the treatment facility, the waste's volume is reduced into its minimum volumetric size by separating out non-contaminated fractions and decontaminating when possible. The waste is then stabilized to prevent environmental contamination. For instance, vitrification, where silicon bearing materials are heated until they melt and form a glass, tremendously lowers the leaching rate of the waste.

Stabilized waste is then transported to a storage facility. The storage facility can be either an interim (temporary) facility or a long term (permanent) facility. Depending on the waste type, it would be sent to a different facility. Currently there is no licensed facility that can take mixed waste. Some hazardous wastes can be sent to an incinerator for final disposal. Low level radioactive waste is sent either to a federal repository or a commercial facility.

The JIT vision for remediation views the ultimate disposal facility as the 'customer' and the retrieval operations at some waste site digface as the supply of raw materials. Through the use of network services like Email on the Internet, distant facilities could inform shippers bringing the material to them that their facility is ready to accept additional material. The shippers would then draw off material from Fernald's interim storage facility. Interim storage would then be ready to accept more treated waste. This chain continues back to the digface. As a practical consideration, some short term buffer space would still be required, though this technique would help minimize interim storage requirements. By communicating these requests electronically, they can be efficiently carried out and organized for optimal equipment utilization, especially when most operations remain at constant flow rates so that a priori demand and equipment needs can be predicted. 
In order for this vision to be realized, a seamless information and material flow must be built out of deterministic, predictable elements that are linked together. 'Factory' operations can be optimized and needs can be prioritized and efficiently dispatched when under centralized control and administration. The Fernald sitewide database will be able to provide the data necessary to build this dispatching network. SGV's can then be used to provide predictable material flow between processing operations even when the specific job requests often shift in volume, location and type. The database, SGV's and their application will be further described in subsequent sections of this document.

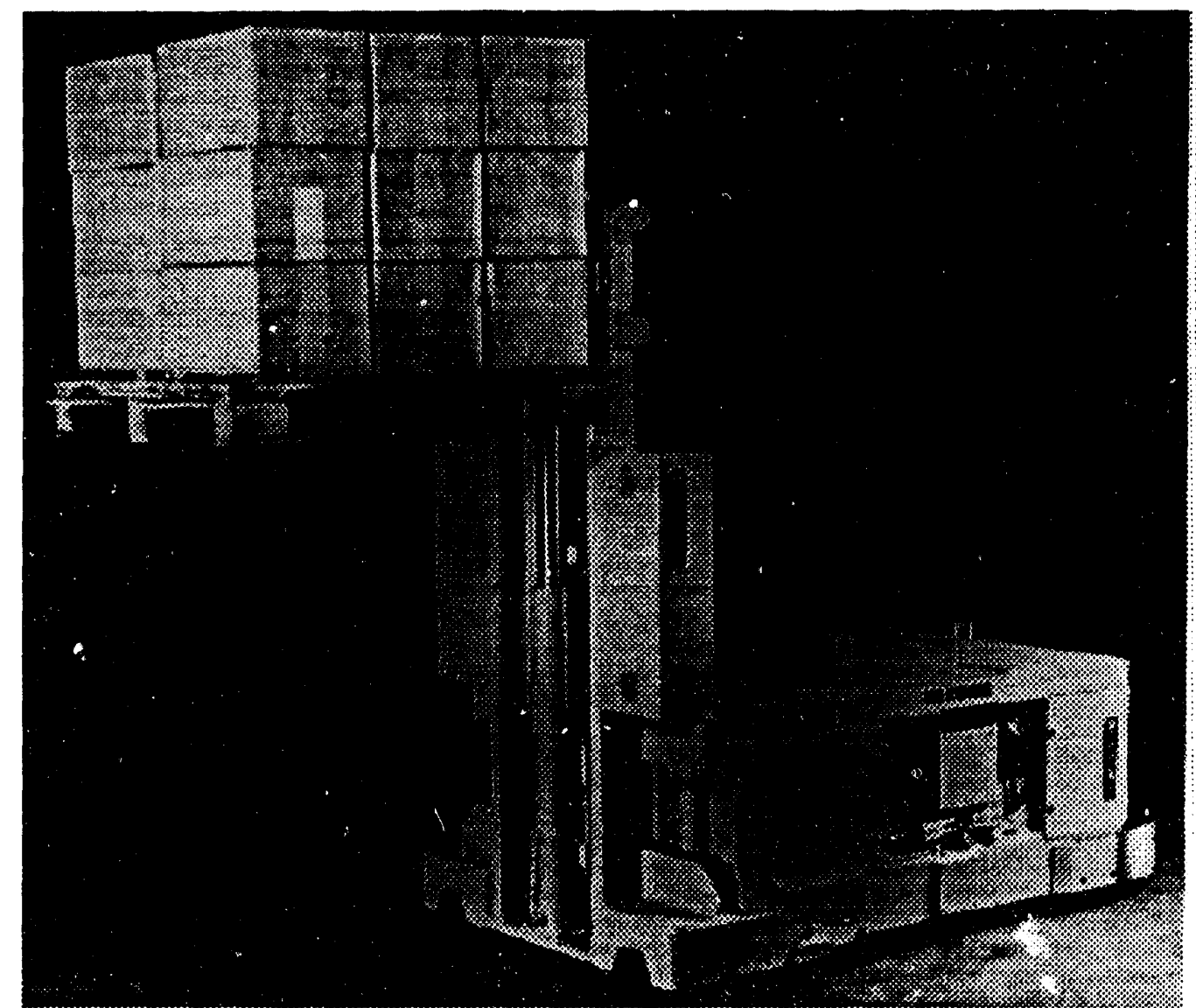

Figure 4 An automated-guided vehicle with lifting capability

\subsection{Self Guided Vehicles}

The SGV is a new type of self navigating vehicle built upon previous industrial and academic efforts. The two areas most closely linked to SGV's are Automated Guided Vehicles (AGV'S) and mobile robots. AGV's are commonly used in industry, increasing efficiency, cost effectiveness and predictability of warehousing and indoor material transfer applications, amongst others. 
Mobile robots have been under development for two decades. They have demonstrated the ability to navigate in partially unknown environments, to sense obstacles and avoid them safely, to interact remotely with host computers, and perform meaningful tasks in many applications.

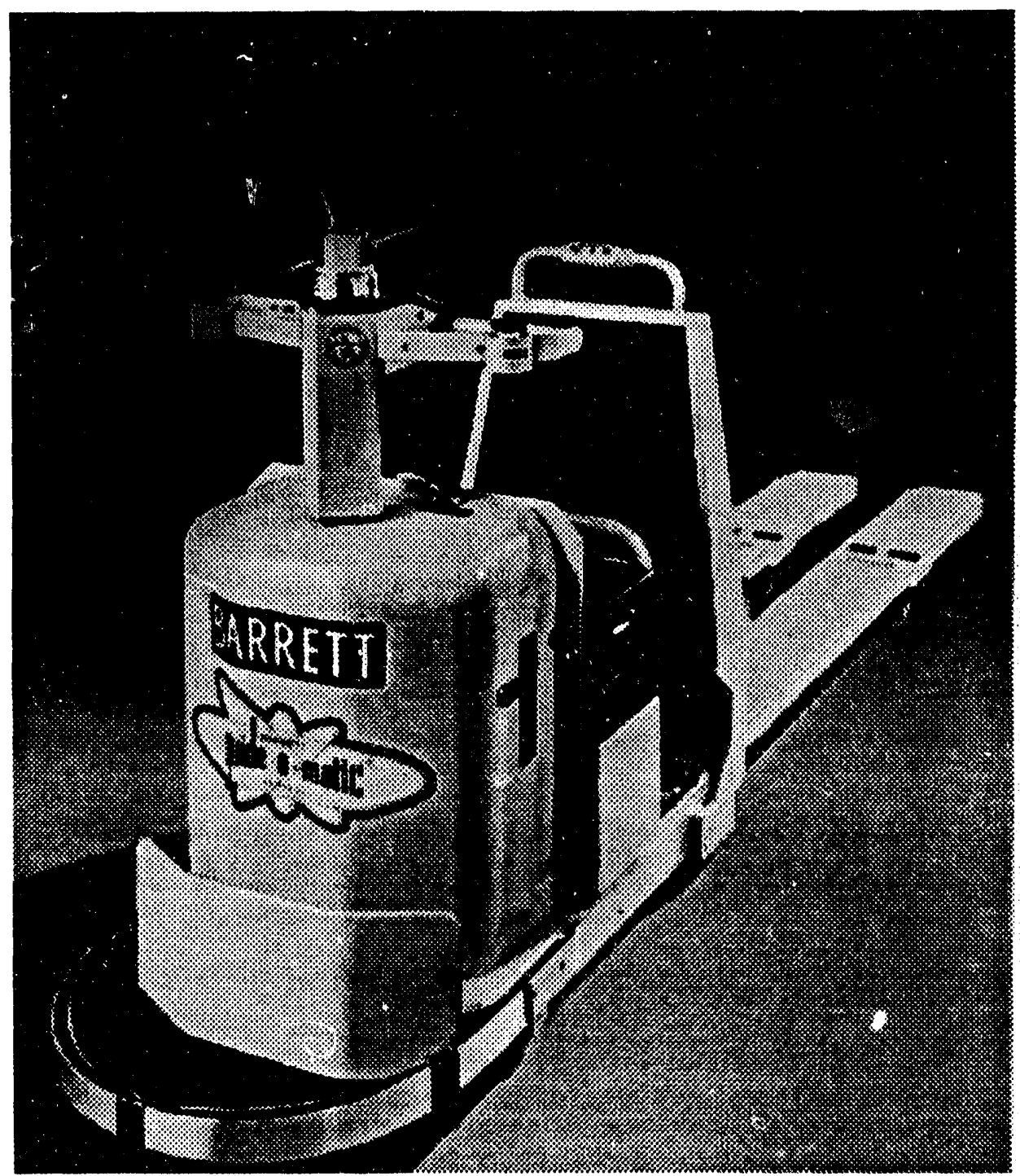

Figure 3 An automated-guided pallet vehicle

What differentiates SGV's from AGV's is the dependence on wires, tape, or track to guide the vehicle. AGV's must have these continuous landmarks because they are not able to navigate on their own. SGV's include the navigation techniques that have been developed for mobile robots, and thus are able to roam wider areas both indoors and outdoors. They are also known as freeranging vehicles. 
SGV's free system designers from having to determine in advance the routes that the vehicle must follow. They allow more than one vehicle to pass on a single route. This saves money both for both initial costs and subsequent modifications. Some SGV's are already commercially available, though no system exists that addresses all of the specifications required for SGV operation at DOE sites. Figures 3 and 4 show two commercially available products.

There are several different design challenges that will be required to build SGV's that can be used at places like Fernald. Particular elements that will have to be specified and designed include the vehicle, lifting and drum grappling apparatus, navigation system, other on-board sensors and controls, operating procedures, centralized optimization and dispatch controls, system layout and deployment, and electronic data links both to other sites and the on-site waste database. In each of these areas established technical approaches exist.

Some of these design decisions depend more on management and operations procedure selection than technical design. However, these procedures need to be optimized to fully utilize the benefits of computer integrated SGV's. Thus both system technologists and operations management must undertake multiple iterations through the whole list of design areas before any one area is 'frozen', due to the strong competition and interdependency between each design goal.

The next subsection descrit. s likely sources of funding, project management, and technical resources. The development proposal for the DOE SGV's is found in section 5. Further discussion of what is available for each of these areas both in academia and industry is found in Section 7.

\subsection{Resources for system development}

The Robotics Technology Development Program (RTDP) within OTD focusses on developing robotic systems that address real needs in the DOE Environmental Restoration and Waste Management (ER/WM) community. The scope of OTD activities is limited to the development and demonstration of systems, and does not include the operational field deployment of proven techniques.

Generally, development work is performed by national laboratories, industry, universities, and/or the DOE sites. This report and its companion, the SGV State of the Art Survey, are funded by the Mixed Waste Operations (MWO) coordination area of the RTDP, operating out of the Savannah River Technology Center (SRTC), one of several sites where robotics work is coordinated for the entire RTDP community.

The proposed SGV project would continue to be administered and funded under the aegis of MWO at . RTC. Savannah River roboticists have been involved in the development of several mobile robot systems, similarly comprised of commercially purchased robot bases that have been enhanced and modified with additional computers, sensors, and programs. 

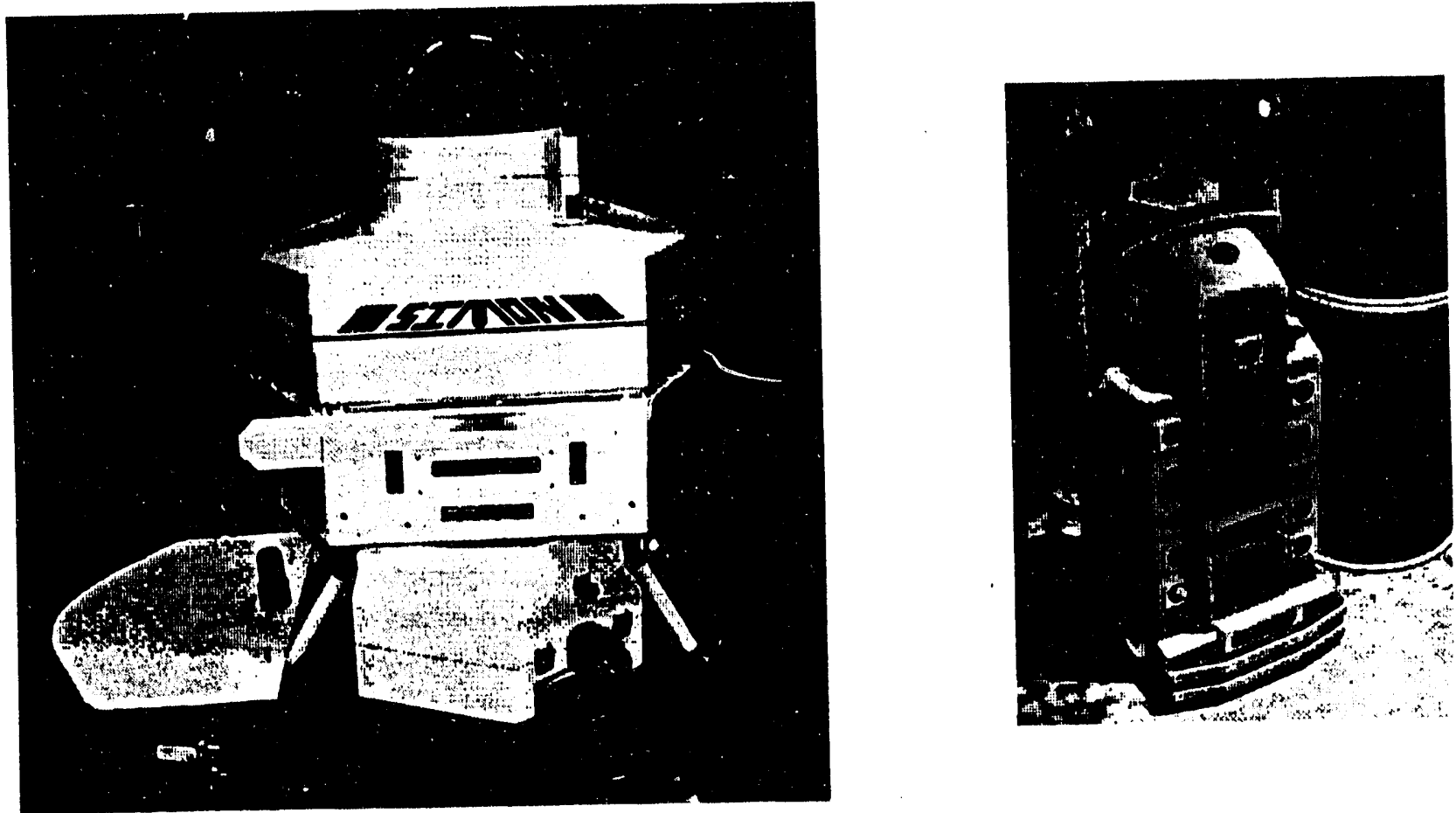

Figure 5- Previous SRTC robots SIMON (left) and SWAMI (right)

Fernald and SRTC have been closely cooperating on one such robot, the Stored Waste Autonomous Mobile Inspector (SWAMI). This mobile robot collects images of drums and then analyzes them for indications of defective drum walls and seams while surveying the floor for elevated contamination levels and verifying inventory locations. Fernald will be the field demonstration site. Figure 5 shows SWAMI on the right and its predecessor, SIMON, which is used soley to create radiation maps.

Oak Ridge (ORNL), Sandia (SNL), and other DOE national laboratories have extensive robotics expertise that can be used constructively in the development of SGV's. Sandia leads the CrossCutting and Advanced Technologies (CC\&AT) coordination area of the RTDP. Their scope and expertise includes high level controls and sensors as well as some full systems. A supervisory control package, the GENeric Interface for Supervisors and Subsystems (GENISAS) can be used to link the SGV's multiple intelligent subsystems. Oak Ridge has a long history in remote systems and robotics and extensive experience in manipulation, sensors, real time controls, and vehicle automation. SRTC will be able to contribute their experience in mobile robot navigation. Structured lighting, available from several national laboratories and a few vendors, may be used to map the environment in which the SGV's operate. 
Universities can also potentially contribute to the SGV project. Several have extensive robotics programs and experience in field demonstrated mobile robots. Other areas that might be useful include Operations Research for SGV system optimization, sensors, and controls. Commercially available vehicles from the materials handling and remote handling industries can be obtained. Figures 3 and 4 showed two examples. Other available vehicles have been identified that have excellent turning capacities, some with arms that have high payload and reach abilities. Many can be remotely controlled with wireless or tethered pendants. A small number of available vehicles are self-navigating.

The DOE has a limited membership in the Material Handling Research Center (MHRC), a multiuniversity research group originally supported by the National Science Foundation (NSF). Collectively they have a great amount of experience in warehousing, logistics, AGV's, and optimization as well as some pre-existing software.

The DOE Transportation Management Division (TMD) has agency-wide responsibility for all freight transportation programs. They have recently begun an effort to integrate, improve, and automate, as appropriate, a number of DOE-wide transportation functions. The Automated Transportation Management System (ATMS) will implement electronic document handling, integrated logistics at the inter-site level, system-wide report generation, motor carrier evaluation and other functions.

The ATMS's scope is probably too wide for it to be directly useful at individual sites. However, integration with the ATMS could yield additional benefits in optimization, efficiency and paperwork reduction. It is scheduled for completion in 1995. Other presently undiscovered activities may also be occurring under the TMD and, for these reasons, SGV developers should explore ways to interface with them on the SGV system. This and the other mentioned resources can all be tapped in the quest for the best and least cost solution to the DOE material handling challenge.

\subsection{Information management}

It should be emphasized that the maximum benefit from SGV's will only be obtained if they are computer integrated both to each other and also to the information database used to dispatch operations and track results of activities. In this section, a site-wide database that is under development at Fernald will be described. It will form the foundation for an integrated system that can go beyond tracking to resource prediction. Further enhancements to support automated dispatch of many of the remediation activities would be the next logical step towards developing a controllable and predictable ER/WM process using systems analysis tools. 


\subsection{Fernald's waste database- SWIFTS}

The Sitewide Waste Information Eorecasting and Tracking System (SWIFTS) is a new, userfriendly waste management database that will quickly and accurately obtain all necessary information concerning sitewide wastes. The existing databases are not integrated nor accessible from all on-site users. Redundancy and inconsistency of information have resulted. Bar coded ID's are not yet used as the identification key for many waste containers on site. SWIFTS will encompass and/or supersede all present databases pertaining to waste streams, as well ss providing new functionality that allows forecasts of future waste storage, shipment, and treatment requirements.

All information pertinent to a particular container will be kept in one record, keyed off of its barcoded ID. Databases on site that will be superseded include the All Materials Inventory (AMI), which tracks containerized waste; The Material Evaluation Forms (MEF) which keep tabs on contents and sampling history; And The Material Control and Accountability (MC\&A) database that tracks nuclear materials for reports to the DOE. The new database will automatically generate manifests and other required paperwork in addition to the standard reports.

SWIFTS will be written in the ORACLE database language and will support client/server relationships between users terminals and the database. It will be available from all nodes on the site's Ethernet network. It will build upon the previously developed Stored Waste Information Tracking System (SWITS) from Hanford. The use of ORACLE and kinship with Hanford's SWITS database will enhance the portability of any interfaces developed between SGV's and the database. ORACLE can call $\mathrm{C}$ programs and can be called from $\mathrm{C}$ programs, further facilitating integration and portability.

The main difference between SWIFTS and Hanford's SWITS is the 'F' for forecasting. SWIFTS can track material from its present position in situ to the filled, bar coded container headed to a disposal site. It would look upon one site, perhaps a waste pit, as a 'bank account', debiting the pit and crediting pre-bar coded containers as the material is retrieved and filled into the drums. The goal is to be able to forecast future storage, shipping, and waste treatment resources. Shipping and sampling schedules will be generated automatically. Shipping documentation will no longer be written out in longhand.

Clearly some paper will need to remain so that proper signatures and approvals can be documented. Not too long from now, however, electronic signature research will render this obsolete also. The use of networks like Internet could speed communications from and to disposal sites, sample analysis laboratories, material suppliers, and DOE and EPA overseers. Links to the ATMS may also be required. The result of this connectivity would be rapia response to outside factors which affect site remediation operations and productivity, and quicker, more complete reporting to DOE offices overseeing the site's activities. 


\subsection{Operations integration opportunities}

SGV's can operate independently and with decentralized control and dispatch strategies, implemented and running on board the vehicle. Neither database integration nor site-wide operations dispatch are essential to the success of the proposed SGV development effort. Furthermore, even without SGV's or other automated equipment, centralized dispatch makes sense when the information in the database is truly accurate and up to date. However, greater benefits would result from combining SGV's with centralized dispatch.

The SWIFTS database at Fernald will improve the reporting, consistency and accessibility of the static information about waste materials on site and provide some forecasting features as well. SWIFTS will provide a strong foundation on which a centralized operations control and dispatch functions can be added.

The more additional operations that can be brought on line, the less paperwork and time will be needed to track and control them. Treatment processes, being fairly predictable and already under computer control, will be easily integrated. Retrieval operations will often have a degree of uncertainty and a manual labor component, so these could be more difficult to dispatch and control this way. Specification of the amount of material to be extracted in a given day, and notification to the SGV system of the availability of filled containers for pickup, could still be brought on-line without the operations being directly computer controlled.

A centralized dispatch and traffic management system dedicated to SGV functions only could be implemented as a first step towards more complete system integration. Shipment schedules, treatment plant output, and on-line transport requests entered by authorized personnel over the network would be assembled and piioritized by the dispatcher. The resulting daily schedule could be modified in real time if additional, high priority requests are entered at any time. The waste database would be accessed to determine the oldest drums in a storage facility so that shipments to disposal sites are selected based on First in First Out (FIFO), as well as inventory verification. Content records for the containers loaded in a truck trailer could be doubled checked before loading to insure waste stream compliance. Accurate records of shipment activities could be automatically maintained.

\subsection{Proposal for the development of self guided vehicles}

The proposal presented here is preliminary and is based upon early investigations of both site needs and available technologies. The SGV concept proposed here results from a Fernald site materials handling requirements study conducted in early 1993. Its scope is limited to the development of a single SGV that is designed to cooperate with other members of a fleet, and also with a central control computer.

This central computer will link with the site-wide materials database and have an SGV dispatch system with a limited number of rules. More complete SGV deployment optimization and implementation of an overall operations optimization and dispatch system is beyond the scope of the SGV robotics project. However, this site-wide dispatch system is a potential companion project that would multiply the benefits available from the SGV. 
Commercially available hardware and software will be used as much as appropriate and then modified so as to enhance the likelihood of project success, system reliability and maintainability. In this section, the project plan, its motivation, the three phases, and the benefits of the systems are described.

Funding has not been secured at this time though it may possibly be supported by the RTDP through the MWO coordinator. Specific dollar figures and schedules cannot yet be accurately presented. However, it can be generally stated that developing one vehicle through the phases outlined below will take three to four years and cost several million dollars (2-5). The Phase 1 costs will be low. Later phases of the project will be more costly but are also contingent on success of previous demonstrations.

Splitting the project into phases will allow site personnel to grow more accustomed to working around and operating the SGV's. Safety and quality departments will probably have many concerns about the safety and reliability of these systems. These can best be allayed through demonstrations, positive experiences with their use, and some time to adjust. Another advantage of a phased approach is that some of the newer technologies, like structured light mapping systems, will further mature in the next few years. Established systems will also improve, such as the speed and memory of computers.

\subsection{Motivation}

During the course of remediation activities at Fernald, millions of cubic yards of material will be retrieved, treated, stored, shipped and disposed. Present material handling methods rely on manually driven trucks, exposing workers to radiation when working in contaminated areas or transporting gamma ray emitting waste. The clothes worn to protect the drivers from potential contamination must be replaced after each of the four breaks during a workday, resulting in additional secondary waste and lost productivity.

For several reasons previously mentioned, fork lift utilization is not optimally efficient at present. Directly matching increasing shipping volume with increasing numbers of workers and fork lifts, used as they currently are, will further deteriorate productivity due to aggravated traffic and logistics problems. Dispatching is done manually, which does not optimize system efficiency. Dispatches will become increasingly unresponsive to real time requests as the volume of scheduled and unscheduled delivery requests increases. Shipping manifests and other documentation that could be handled electronically still require paperwork for each container in a shipment.

Containers can get damaged as they are being moved, especially when they are large or extracted from tight spaces. Direct evidence can be found on the support pillars in some storage areas, where multiple scuff marks present a record of previous encounters. FIFO shipment of materials offsite is difficult to implement without constantly rearranging storage areas. Consolidating storage areas (filling in the empty spaces) is time consuming. Accessing drums in storage areas for overpack or sample access this is often required and is a tedious and time consuming task. 
Radiation shielding is not as much of a problem at Fernald as other DOE sites because so little gamma ray emitting material is found on site. However, some materials with radiation hazards have been and still remain on site. Thorium has been stored in drums at Fernald for many years, and some of the containers had rusted badly. Recently, the Thorium was approved for offsite shipment and a specially designed fork lift was procured to assist in the movement of the drums to overpack stations. Since Thorium is a gamma emitter, lead shielding had to be custom installed inside the driver's cab. It significantly reduced visibility and so two cameras were mounted to look ahead and provide the operator with two monitors above the dashboard showing the view outside. Because of the potential for airborne contamination, the air inside the sealed cab was purified with HEPA filters. Other modifications were also made.

Unfortunately, the vehicle did not perform as intended and had to be abandoned. Visibility was extremely limited and the monitors do not provide an intuitive feel or depth of field. Trying to drive the truck in this way was also tiring to the driver. Imagine a situation where a number of these vehicles are needed. Overall productivity would fall as operator difficulty and fatigue increase. Traffic problems could be a nightmare given the reduced visibility.

In summary, a key driver for the SGV project is the desire to keep radiation exposure to workers As Low As Reasonably Acheivable (ALARA). Additional drivers include increased material throughput, the need for accurate documentation and records, traffic and logistics issues, and the need for a low-cost, predictable systems solution integrating both material and data flow within and across site boundaries. Three distinct developmental phases have been defined. This will permit progress to be gaged prior to further financial commitment.

\subsection{Phase One: Human assist}

The first phase of SGV development will be enhancements to manually operated fork lift trucks, dispatch software and hardware. Sensor data and models of the container, fork lift and environment will be merged to provide operators with warnings of impending collisions when maneuvering in new (unknown) surroundings. This is intended to develop a mapping system that will be able to scan an area for the exact position of containers to be picked up, as well as performing collision avoidance and, eventually, autonomous navigation.

It will provide a basis for Phase 2 development. It will also increase the visibility and personnel confidence in the types of safety systems used for the SGV's. For instance, large boxes often get bumped at the comers that the operator cannot see, as the vehicle swings around in a cramped area. A realistic demonstration will be set up, with performance criteria determined in advance, to show obstacle detection, the first step in collision avoidance.

Dispatch features will also be developed in Phase 1. Container relocation orders will be sent directly to an alphanumeric display mounted on the fork lift by wireless means. It will tell the source and destination of the next transport job for that vehicle. Bar code readers may be included to demonstrate automated inventory updating as the containers are moved. Optimization software running on a central workstation will consider scheduled and previously unscheduled requests and available equipment, in order to determine the dispatches in real time. The activities of other vehicles and site operations will be simulated in order to test the optimization without requiring a full-blown system. 


\subsection{Phase Two: Structured environments}

In Phase 2, the SGV vehicle itself will be procured. It will require a 4 ton (8,000 pound) capacity, in a compact package with a high degree of maneuverability. It should also be capable of outdoor operation in rainy, cold, or hot conditions. It will have to be able to enter truck trailers and rail cars, and travel on fairly narrow paths and aisles.

The second phase system will also include grappling hardware, and navigation software, as well as t'e collision avoidance and dispatch modules from phase 1 . It will be able to pick up items ranging from loaded pallets to individual containers. It will be able to enter and operate in truck trailers and center aisles in storage areas. It will climb ramps when fully loaded as required. It will be able to identify containers by their bar-coded labels.

The grappling hardware will be designed to pick up and deposit 55, 85, and 110 gallon crums gently and safely, as well as B-25 boxes and loaded pallets of standard design. Special adapters may be designed to prevent drums from tipping without having to band the drums to each other and the pallet. Navigation inside buildings will be demonstrated, with robot obstacle avoidance and path planning for both the vehicle and grappling hardware. This will use the structured lighting and mapping previously demonstrated with more sophisticated algorithms for determining collision free paths.

A demonstration of either trailer truck loading or storage area aisle stacking/de-stacking will be defined and used to evaluate the vehicle's performance and reliability before advancing to the final phase.

\subsection{Phase Three: Unstructured environments}

The third phase SGV system will be capable of autonomous operation on a variety of surfaces, indoors and outdoors, and amongst people in a less structured environment. In this phase, system integration and fleet design will also be accomplished. Routes, pickup/delivery $(\mathrm{P} / \mathrm{D})$ points, and data connections, as well as other SGV system design issues, will be resolved. Hand-off between two SGV's at a contamination zone boundary, and rad surveying systems and procedures for the container crossing the boundary, will also be addressed. SGV operation at retrieval zones will be explored. These areas will be the most problematic due to potentially uneven roadways and constantly shifting physical layouts.

Outdoor operation will be between a limited number of facilities and along specific portions of the road, so that pedestrian and vehicular traffic can be controlled in the early stages. As the SGV proves its safety, reliability, and obstacle avoidance, the vehicular restrictions will be relaxed as appropriate. Additional applications of the SGV will be tested and Standard Operating Procedures will be developed. Industrial partners will be sought to help commercialize the final system developed. 


\subsection{Benefits of the final system}

The ultimate autonomous material movement (SGV) system planned will be a set of automated vehicles that are dispatched based upon real time requirements. It will permit much more efficient and deterministic operation. When all dispatches are issued by a central program agent, fewer vehicles will be required because of fuller utilization of existing resources. Traffic congestion in some areas, and with high volume (multi-vehicle) transfers, will also be reduced.

Potential radiation exposure to vehicle drivers from the waste, or contamination from spills, will be eliminated since there are no drivers. The iikelihood of collisions will be reduced by previewing the path to be taken with the container and checking for any possible collisions against an accurate, sensor-updated model of the environment. The vehicles will be able to consolidate container placement in storage areas automatically. They will also be able to access a specific drum in a close packed storage area, even if that means de-stacking and re-stacking multiple pallets.

FIFO shipments will be possible without having to constantly rearrange the containers. Multiple SGV's will be able to work in closer proximity with fewer traffic problems since their movement is coordinated by a central control agent. Multiple shift operation seven days a week will be feasible. Images of the containers in the as-loaded configuration could be recorded to prove that the containers weren't damaged prior to shipment. Permanent records of the activity will be recorded and timestamped on unalterable media when appropriate. Paperwork will be reduced and operational predictability will improve.

\subsection{Fernald site requirements}

Since the remedial investigation and feasibility studies are still not completed for all the CRU's, facility requirements and treatment techniques as well as their locations, have not yet been determined. The ultimate mix of off-site shipment versus on-site storage has also not been determined. Hence it is not yet possible to define the routes, pickup / delivery locations, and exact volume of material that will be transported. Therefore the discussion of Fernald site requirements is by necessity quite general at this time.

ALARA concerns will be significant for the handling of much of the waste retrieved and transported. This issue alone has already been prominent enough to merit special equipment to protect the truck driver for the case of thorium transport. Certainly the best protection is to remove the driver from the vehicle entirely. This would also reduce the cost and secondary waste from contaminated protective equipment.

The strongest evidence that can be submitted to support the site's need for SGV's is the amount of material that is presently on site and that will have to be removed and treated. Approximately 115,000 drum equivalents of waste are presently in containers on site. Approximately 1,250,000 cubic yards of material will need to be treated and packaged for shipment or disposal according to the CRU Waste Information Manual prepared by CRU3 project integration in mid-August 1993. With B-25 boxes holding around 2.5 cubic yards, 50,000 B-25's will have to be transported through several process steps. Also, the demand for material handling will not be constant over time; Peak demand could be extremely high with intermittent lulls. 
In addition to the large amount of material to be moved, there is a definite need to integrate the record keeping and report generation more closely with the actions, such as drum movement or shipment. This data integration need can be solved by coupling the site-wide database with the actual processes and equipment through automated dispatch, tracking, verification, documentation and paperwork generation. An example of this integration can be demonstrated with the SGV project. Hopefully this can facilitate full scale integration further down the road.

The material handling systems selected will have to be flexible and robust enough to navigate in an environment that will be constantly changing. The area will resemble a construction site and thus roadways may move or be rough. Ease of decontamination, decommissioning at the end of its mission, and compatibility with regulations and safety guidelines will also be important. It should allow for low-cost, high throughput container transport with minimal traffic impact.

In this section, the results of a previous materials handling study are presanted. This gives some insight into what the remediation site will look like at the time when the SGV's become available for operations support ani show some of the alternatives to SGV's. Site transportation requirements are presented next. Applications for the SGV's at Fernald are then described. A brief description follows of the safety and quality approvals that the SGV will be subject to prior to its use on site. The section concludes with a description of site transportation procedures and oversight groups.

\subsection{Results of a previous material handling study}

A materials handling study was conducted by Parsons Engineering for the Engineered Treatment, Packaging, and Staging Facility (ETPSF) in 1991. Though it was based upon plans and assumptions that have since changed, it provides some insight into the projected situation that will be encountered at the FEMP. It is based on a waste removal, treatment. and on-site disposal remediation option previously identified in another study. The on-site disposal is the most dubious part of this option, given the direction that alternatives screening is progressing towards in late 1993.

The ETPSF would consist of three separate buildings. These are a vitrification facility, an Extraction/solidification facility, and a decontamination facility. With each facility operating 250 days per year, all 2.2 Million cubic yards of material (more than recent estimates) could be treated in 10 years, if multiple shifts were used up to 7 days per week. This study sited the decontamination facility north of the scrap metal pile, near building 78 . The solidification and extraction facility was sited southeast of the OU-1 waste pits that would supply the bulk of its incoming material. The vitrification facility was sited East of the K-65 silos, once again placing the facility near the primary source material. This is still the most likely location for the vitrification facility, and a pilot plant may be erected there shortly if CRU4 plans are approved. 
One interesting aspect of the study was an evaluation of on-site transportation options. Several methods were evaluated using weighted selection criteria to produce a final score. These weights are subjective and lead to some inaccuracies in their final conclusions, though the criteria themselves are useful. Note that predictability and data integration were not addressed in this list.

\begin{tabular}{|c|c|c|}
\hline 5 points & 10 points & 20 points \\
\hline $\begin{array}{l}\text { Exse or deconlanimation } \\
\text { Ense of decommissioning } \\
\text { Maintenance/reliability } \\
\text { Equipment availability }\end{array}$ & $\begin{array}{l}\text { Capilal cost } \\
\text { Operating cost } \\
\text { Throughput } \\
\text { Traffic impect }\end{array}$ & $\begin{array}{l}\text { Compatibility Wilu regulations } \\
\text { Protection of health \& Environment }\end{array}$ \\
\hline
\end{tabular}

The methods evaluated were: Off-highway dump truck, pneumatic conveyor, belt conveyor, slurry tank truck, slurry pipeline, enclosed dump truck, containers on flatbed trucks, and rail transportation. The slurry methods has the highest score, with containers on flatbed trucks coming in second. This latter method is probably closest to the SGV's attributes. Slurry has the advantage of providing containment for the material and flexibility (through the use of hose) in delivery and pickup location. However, water must be added to the material and then subsequently removed, and some materials are not amenable to this method.

In addition, there is significant resistance to the idea of plumbing and installing a complex, fixed piping network in a facility that is supposed to be torn down. This aversion also affects other fixed options such as pneumatic or belt conveyors. SGV's or containers on trucks are more flexible and will not leave as much equipment to be decommissioned after the primary clean-up is complete. Methods that do not use standard, approved containers (Enclosed or off-highway dump trucks and rail transport) would require special regulatory approval and this is a significant disadvantage.

\subsection{Site transportation requirements}

The overall site need is for material handling systems that can increase the safety, efficiency, and throughput of material transfers both inside and between facilities. Truck loading and aisle stacking/destacking have been specifically identified as potentially useful applications. Other functional requirements were already discussed in the introductory section 6.0.

A unique aspect of transportation at Fernald is the controls that exist to prevent the spread of contaminants as vehicles pass from one radiological zone to another. Figure 5 shows the familiar sight of a vehicle being monitored as it exits a zone of higher contamination. This survey is time consuming and is often incomplete due to the complexity and inaccessibility of many vehicle surfaces. If a rad tech is not immediately available, wait times can be even longer. 


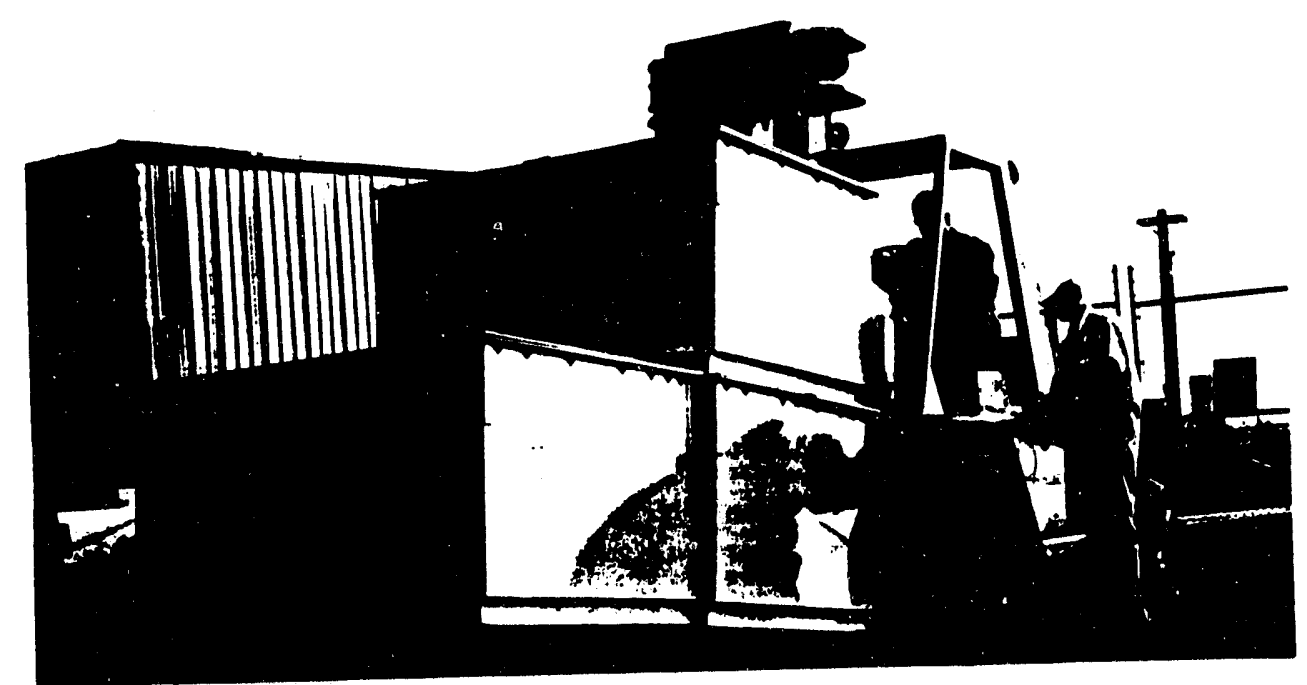

Figure 6- Radiological surveying of a truck

One solution to this is to have vehicles assigned to each contamination zone and develop a procedure to hand the containers across the boundary and survey them at the boundary. For a simple geometry like the B-25 Box, this survey could be automated. The computer dispatch of the vehicles would be used to coordinate their schedules for maximum efficiency. The survey's results would be automatically recorded for documentation purposes. The survey equipment would be calibrated and functionally tested intermittently to insure that the system is working properly.

In early phases, the SGV will only operate indoors, but eventually it will be able to transport loads between facilities and retrieval points. The number of routes between facilities will be minimized to avoid disruption to existing traffic and to reduce the number of alternatives the computer considers during optimization (for shortest route travel, for instance). Cost effectiveness and flexibility are required of any system installed at the FEMP. Travel over existing roadways is required so as to keep the installation and path modification costs under control. Lanes will be either two SGV's wide, or single width with 'rest areas' available for two vehicles to pass.

Safety engineers will need to work with the SGV developers to determine what controls, if any, should be required on the vehicle travel lanes. The concern would be for collisions with objects or people. With several types of obstacle detection available, such as ultrasound. laser, optical, visual, or tactile, obstacles in the lane should not be hazardous to the vehicle and vice-versa. Painted areas on a roadway with posted warnings to avoid the lane should be sufficient. That way, SGV's. vehicles, or pedestrians could use the entire road if necessary. 
The vehicle's top speed and reach will be designed so as to address safety concerns. When properly scheduled and dispatched, the vehicles do not need to travel fast in order to provide good throughput. Five MPH, or the pace of a brisk walk, should be sufficient for early systems. This is especially true at the compact Fernald site, where the longest conceivable route is under one mile, or less than 12 minutes at $5 \mathrm{MPH}$. It is important to demonstrate the safety of these systems at a low speed in order to gain acceptance. This will be enhanced by having many 'Mushroom' emergency stop switches located at easily accessible locations. Experience on site with the SWAMI robot will hopefully have already convinced many that obstacle avoidance can work well in field applications.

SGV's operating outdoors need only enough reach to lift the container clear of the ground. Inside storage facilities they could need to reach ten feet or more to retrieve a pallet at the fourth (highest) stacked level. When unneeded, high reaches should be avoided due to tipping hazards. Heterogeneity between these applications can be provided with a detachable lifting mechanism on the SGV that is changed depending on a particular unit's application. The receptacle could also be used to change between drum and fork lifting tools as required.

\subsection{Applications}

The SGV developed will need at least an 8000 pound capacity and 12 foot high maximum reach. This is sufficient for a loaded pallet of drums, a single filled B-25 box, or several empty containers. ISO boxes are too large to be practical for the initial system. While they hold 17 times as much volume, they are also unwieldy for intra-site shipments. They are always lifted crosswise from the center since this is where the fork receptacles are located. Thus, since the twenty foot long container is wider than the road, all traffic is blocked when being transported down a road by forklift. Lifting the box onto a truck trailer and then driving the truck away is fine for off-site shipments but would cause great inefficiencies and traffic congestion if used for the extremely short hauls at the FEMP.

The following is a list of present and future site operations at Fernald that are amenable to the use of the phase III SGV as previously described in section 5.4:

- Container transport

-Intra-facility

-Inter-facility

- Empty container supply

- Waste Storage Area (WSA) operations

- Consolidation

- Drum access

- Shipping

-Shipment picking

- Truck loading

- Train car loading

- Documentation and manifests 
The primary application will be the transport of containers through the entire remediation process. This begins with the controlled supply of empty containers to be filled. By controlling the release of shipping containers, the amount of material retrieved in a day will more closely adhere to a master schedule. By 'backhauling' empty containers on return trips to the remediation area, container storage at the retrieval zone can be reduced, while utilizing the SGV more efficiently. A subset of the SGV fleet will be dedicated to operation in higher contamination areas. The loss in dispatch flexibility by splitting the fleet will be more than made up by the time saved by not surveyin entire vehicles as they pass. Handing off the load between SGV's at the zone boundary will also reduce the chance of cross-contamination, still possible with manually surveyed vehicles because of the difficulty of adequately monitoring large, geometrically complex machines.

The SGV will have to be able to identify containers by their bar-coded ID's in order to insure that the right one is picked up. Once moved, inventory records can be automatically updated with the container's new location. This will be a great help since tracking specific waste containers or waste streams wili be more difficult as the volume processed increases but tracking requirements remain fixed. The SGV can potentially check compatibility of waste containers as they are set together. The bar-coded ID would be used to access the record of contents for a particular container. This is important because of restrictions on the type of waste constituents that can be stored together. They are intended to prevent adverse reactivity if two content types spill and then mix.

Outdoor transport will be limited to remediation operations- incoming receiving, movement of supply materials (except containers) and other low volume, high flexibility outdoor applications will be omitted. A few routes will be determined between the retrieval area, processing and storage facilities, empty container storage, and shipping points. The design and selection of the routes and pickup/delivery points will have a major impact on the SGV system performance and thus these should be considered carefully in advance. That is not yet possible since several remediation plans are still being considered.

Indoor transport within processing, storage, and shipping facilities will be required. Beyond Fernald, the Mixed Waste Integrated Demonstration (MWID) is planning a modern waste processing facility and has identified automated materials handling as an important component of their facility. Similarly, the SGV's at Fernald should be able to allow for more flexibility in the processing of waste (customized flow patterns through the facility depending on waste type), as well as good cross-contamination protection within the facility.

Once processing is finished, a container will go either to shipping or storage. In either case, the SGV will transport it to the appropriate location based on the dispatches it receives. Inside some storage facilities, many containers will be received and released to shipping in a given day. Tracking inventory and maintaining orderly stacks of drums will be much easier for an SGV fleet. If a drum or B-25 box is randomly chosen for sampling, retrieving it will be much easier, even if it is packed deep into an aisle. Similarly, if a container has been identified as requiring repair, the SGV will be able to disassemble the stacked aisle, and get the container out. As the aisle is torn down, a buffer area would be used to temporarily hold the disflaced vessels. When replaced, the locations of the pallets could be updated, as they could shift position when restacked. 
Offsite waste shipments will be staged and loaded into trucks or train cars automatically using the SGV. The vehicle may be fitted with a camera that records an image of the container in the as-loaded position. This can be used to document labeling and container condition. Two SGV's could be used to more quickly fill the trailer with better traffic control than manually driven fork lifts. Bar-code ID's could be triple checked as the truck or train is loaded.

\subsection{Safety approvals}

This section will concentrate on inspections and approvals that are required by Fernald for the operation of a new piece of equipment. Quality assurance and control is treated separately in 6.6.

The Transportation Safety Committee is responsible for the evaluation of all policies and procedures concerning the transportation of materials at Fernald. They are charged with insuring compliance with Federal, State and Local regulations including OSHA safety requirements, DOE orders and FERMCO guidelines.

Key documents that have to be produced include a work plan, test plan, safety assessment, and health and safety plan. Generally they consist of a brief scope of work, introduction to the system, and specific information as required. The work plan subsumes the two other plans mentioned. Limited procedures for SGV operation during the demonstration can suffice and then can be used to subsequently develop more comprehensive procedures for its use under normal operating conditions.

The Health and Safety plan is developed through a series of iterations between developers and FERMCO's Occupational Safety and Health department. There are issues of concern such as industrial hygiene and safety, and radiological control. Industrial hygiene seeks to assure worker safety from physical and chemical hazards. Radiological control protects them from being contaminated or over-exposed. Fire protection has an interest in making sure the SGV doesn't cause a fire or otherwise spontaneously combust. Safety and risk assessments may also be required as one or two separate documents if the system is perceived as posing a significant threat to the environment or human health.

The use of radio controlled equipment at a Government site is regulated by both the FCC and the DOE. A preliminary repor. indicated that commercial frequencies were difficult to get approved and the frequency approval for the Government bands, from the Interdepartment Radio Advisory Committee, took months at best. The best way around this roadblock would be to use infrared telemetry or keep the power output below $5 \mathrm{~mW}$. It has since been indicated that wireless Ethernet using spread spectrum is also acceptable. 


\subsection{Quality approvals}

For short duration technical demonstrations, the Quality Assurance (QA) department only requires that operating procedures be instituted for its operation during the demo, and that the operators be trained properly in adherence to them. When used more permanently, a greater number of requirements are placed on the system provider. The following discussion refers to the more stringent requirements of a permanent installation.

FERMCO has developed its own internal QA standard called RM12. By design, it meets these other standards: NQA-1, DOE order 5700.6C, and the EPA's QAMS 005-80. Four quality levels are defined to identify the level of checking that should be accomplished when equipment arrives. These levels reflect the amount of custom engineering involved and not the level of hazard to humans or the environment. Several criteria have been developed by QA to check the quality of systems used at Fernald. They are training, documents \& records, work performance, procurement, and independent assessment.

Training must include instruction in the adherence to the pre-established standard operating procedures. These operating procedures may be developed at the demonstration but must be completed before normal operation can begin. The training program must insure that operators are capable of normal SGV operation and have a basic understanding of its major components. It must include training in how to handle various failure modes and to identify and control any resulting effects. This should include souras of variability in performance and the degree to which the operator can or cannot control it. The instruction must be provided by qualified instructors and the training program must be periodically reviewed to insure that it is effective and adjusted as appropriate.

The SGV developer must have a program to control the release and revision of documents and records pertaining to the design of the as-built system. If the SGV automatically updates some of Fernald's databases as part of its operations, the updates must adhere to additional restrictions. The changes must not obscure the original entry. The changed data must have a record indicating the reason for the change, be flagged as changed, and identify who made the change and when.

Standard operating procedures for the system must be developed. The procedures must be validated and verified by technically qualified personnel. A procedure to control the calibration, maintenance, and use of the SGV must be developed. This process can be developed during the demonstration. If possible, these procedures should be traceable to national standards.

QA is also responsible for assuring the quality of procured systems. They implement the appropriate controls to assure the quality of the selection, determination of suitability, evaluation, and receipt of commercial-grade items. The vendor must provide a means of insuring that the parts in the unit will work as they are designed to. The vendor must supply a certificate of compliance to "Buy American" and "Suspect parts" requirements. "Buy American" encourages vendors to use U.S. products where available. The "suspect parts" requirement indicates that parts must not be used or reconditioned and must be up to FERMCO's high standards. 
For a permanent emplacement, the QA department may wish to perform supplier audits to insure that they meet the quality requirements of Fernald. They will also evaluate the supplier's QA program for conformance with quality requirements. The receipt inspection will insure that when it arrives on site it conforms to the established QA/QC criteria. QC is not capable of performing rigorous inspections of electronics, hardware, and software. They may, however, perform full functionality checks as well as inspecting for shipping damage.

\subsection{Site transportation procedures and regulations}

The transportation safety committee is responsible for the adherence of transport activities to applicable and relevant regulations. In addition, the Traffic Control group is responsible for determining on-site movement of hazardous materials, scheduling of off-site shipments and preparing its paperwork. Traffic control provides guidance on the required documents, packaging, marking, labeling, and placarding for shipments. For off-site transport, Traffic Control prepares a Uniform Hazardous Waste manifest to comply with RCRA regulations.

Fernald's Material Control and Accountability department has final responsibility for the tracking of waste on site. It is responsible for documentation and verification of inventory. The Facilities and Warehousing group is then given the current location of the material, the location (on-site) where it is to be transported for off-site shipment, the material type, and quantity. If stored temporarily, it must comply with stored waste regulations and procedures.

Facilities and Warehousing is responsible for loading of the transport vehicle. They must insure that the vehicle is appropriate for the weight and center of gravity of material to be loaded. They also inspect the vehicle itself. They attempt to place material in the vehicle so that the weight is evenly distributed over the vehicle's axles. Additionally, the load is to be placed in a manner that does not restrict the driver's view, access to emergency equipment, or exit from driver's compartment.

All hazardous materials are to be loaded according to DOT guidelines concerning material separation and segregation. Containers should be blocked or braced to prevent movement and to remain stable after restraints are removed prior to unloading. The ends, sides, and doors of the vehicle may not be used to prevent shifting unless designed specifically for that purpose. All sides, sideboards, rear end-gates, and end-boards should be in their proper place and physically capable of preventing packages from shifting or falling. They must insure the use proper tiedown procedures and that no damaged containers are shipped.

Form FMPC-714 (Product Order) and form FMPC Cont-558 (Shipping Order for Nuclear Material) are required for shipments of nuclear material. Form FMPC Cont-3388 (Shipping Order for Hazardous Material/Hazardous Waste-non Nuclear) is used for all hazardous nonnuclear shipments. Form FMPC-ADMS-871 (Miscellaneous Shipping Order) is used for shipment of non-nuclear non-hazardous material. 
Required documentation for the movement of non-radioactive hazardous material includes the following forms; Nonradioactive Hazardous Material Shipment Approval (FMPC-OPR-2947), Material Safety Data Sheet(s), Radiological Survey Report (FS-F-1993-1), Hazardous Material Transfer On-Site Shipment (FMPC-OPR-3292), Shipping Order for Hazardous Materials/Hazardous Waste-Non-Nuclear (FMPC-CONT-3388), Offsite Loading - Tie Down Inspection - Vehicle Inspection (FMPC-SAML-2495), and Vehicle Radiation Monitoring Report (FS-IRS\&T-1596-1). Once these forms are completed the vehicle's bill of lading is completed and signed by logistics administration.

The Code of Federal Regulations Title 49, covers the Department of Transportation (DOT) requirements. DOE guidance on the transportation of materials at DOE sites mostly references DOT regulations. DOE Order 1540.1A Chapter II covers transportation operations for material leaving DOE sites. It states that the packaging, marking, and labeling must meet the regulations contained in 49 CFR parts $171-179$ on the DOT. It also addresses loading operations. "The loading device used to load or unload a shipment shall be appropriate for the dimensions and weight of the package. Loading devices which may possibly damage any packages of a shipment shall not be used." DOE Order 5480.3 states that the shipment of materials must meet with the DOT safety regulations. The following is a listing of applicable regulations and procedures:

Code of Federal Regulations

Title 49 Department of Transportation

Part 171 Subpart C Hazardous Matel.d Regulations

Part 173 Subpart A General

Part 173 Subpart H Radioactive Material

Part 390 Eederal Motor Carrier Safety Regulations; General

Part 396 Inspection. Repair. and Maintenance

U.S. Department of Enerzy

DOE 5480.3 Safety Requirements for the Packagine and Transportation of Hazardous Materials. Hazardous Substances, and Hazardous Wastes

OR 5480.3 Safety Requirements for the Packapine and Transportation of Hazardous Materials. Hazardous Substances, and Hazardous Wastes

DOE 1540.1A Materials Transportation and Traffic Management

OR 1540.1B Materials Transportation and Traffic Manarement

ORIG 1540.1C Materials Transportation and Traffic Management

EEMP Procedures

SSOP-0003 Receivine. On-Site Movement and Off-Site Shipment of NonRadioactive Material

SSOP-0060 Packarine and Loadine Radiosctive Material for OffSite Shipment

SSOP-0068 Inspection of Procured Material, Equipment. Work in Progress and Completed Items

SSOP-0075 Packapine Low Level Radioactive Waste (LLRW in Drums for OffSite Shipment

SSOP-0078 Packarine Low Level Radioactive Waste into ISO Containers for OfSSite Shipment

SSOP-0079 Packaging Low Level Radioactive Waste in Metal Boxes for OffSite Shipment

SSOP-0314 Packine. On-Site Movement and Off-Site Shipment of Material

FMPC-718 Measurine and Calibratine Test Equipment Calibration and Control 


\subsection{Research on the State of the Art for SGV's}

The University of Cincinnati has recently completed a report on the technologies available to build Self Guided Vehicles. This was the result of searching both commercial and academic sources. The scope was both the design of the vehicle and the design of a fleet of vehicles that addresses a particular facility's needs. A generic scenario for the use of SGV's was presented to illustrate typical applications without introducing too much complexity. Technical solutions to the those scenarios were then proposed. The report is available through either the Technology Development Department at Fermco or the RTDP Mixed Waste Coordinator.

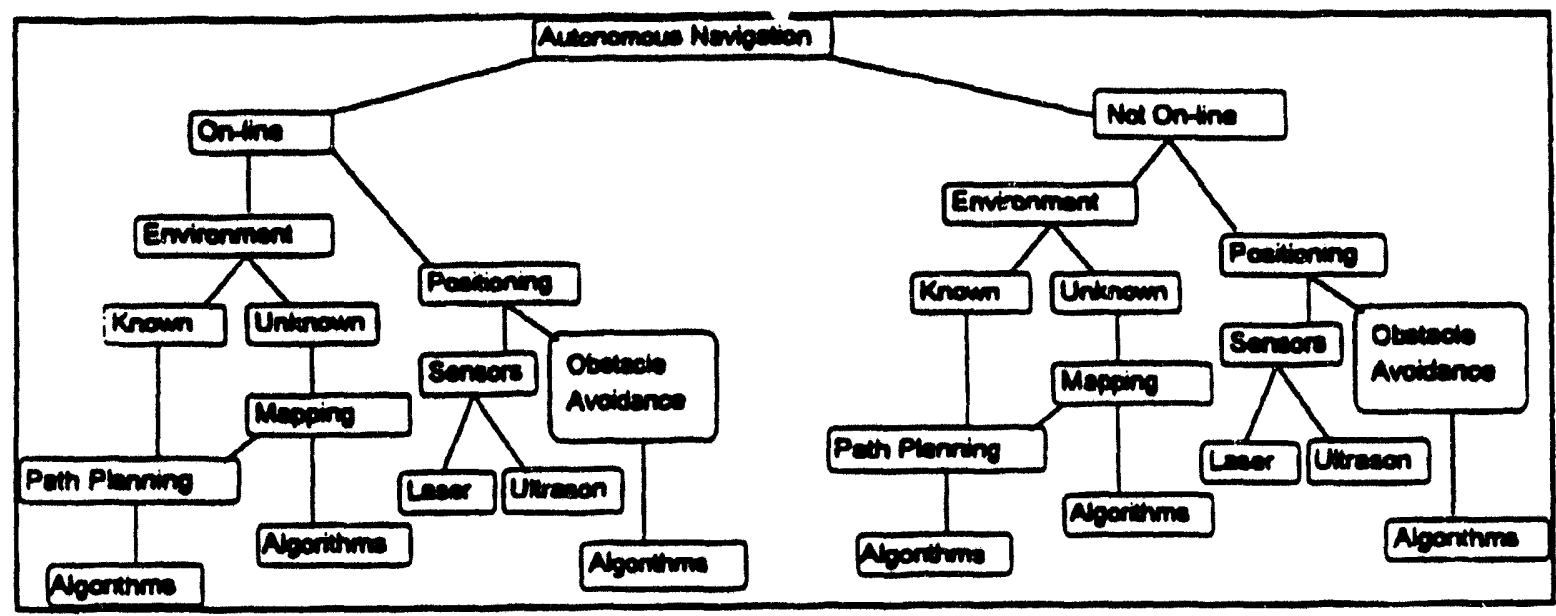

Figure 7 Technology tree of SGV development components

Figure 7 illustrates some of the technical areas that were covered. Autonomous navigation is one of the central requirements for SGV's. Maps must be built in real time from sensor data of the environment. Algorithms are then used to plan paths for the vehicle or grappling equipment in the abstracted space represented by the maps. Vehicle localization, position sensing, path planning and obstacle avoidance were the features of autonomous navigation that were targeted. This included Global Positioning System, inertial navigation, dead reckoning, and triangulation. Map building sensors such as ultrasound and cameras, and representation techniques were explored. Sensors themselves were reviewed in a separate section.

Some of the system design decisions for a fleet of SGV's include determination of the specification of the guide paths, pick-up/drop-off locations, and the design of supervisory controllers to manage the system. This is a type of optimization that is applied to the system during the design phase, long before actual operation. As it turns out, tradeoffs exist between local and global control. If each vehicle has a high degree of autonomy, the central computer will have a harder time predicting traffic patterns, but at the same time will not have as much burden to track and control every SGV. Methods to address these problems were presented and seem to indicate that a reasonable solution exists for the Fernald situation. 
Another type of optimization occurs at the time that job requests are received. This type of realtime responsiveness is known as on-line optimization. Areas for which this is used include traffic management and route planning. Heuristic (rule-based) abstraction and modelling tools, such as Petri nets, were presented. For example, dispatching rules can be classified into 'push-based' and 'pull-based' rules. Push procedures look at the list of materials available for pick-up and then select an SGV to accomplish it. Pull-based procedures (closer to the philosophy of Just In Time) determine destination processes that require a shipment and then determine sources that could fill that need, dispatching a particular SGV according to a different set of rules.

Similar systems were also sought. Commercially available AGV's and their operation in factories were presented. A number of mobile robots that have demonstrated autonomous navigation and/or operation in hazardous environments were catalogued. As those who have parallel parked know, wheel configurations can limit vehicle mobility. The configuration selected will impact the ability of the SGV to maneuver in tight spaces such as the interior of a truck trailer. The kinematics of the steering and driven wheels in an SGV system were reviewed in the survey. In general there is not a concise mathematical description of how to steer a vehicle to a given point and this can complicate path planning. The 'Swedish', or llonator wheel is one wheel that avoids this problem. It can provide motion parallel to the wheel axis in addition to normal rolling motion perpendicular to the axle.

Self Guided Vehicles have been commercially available since at least 1987 . One vendor supplies a number of different SGV's with lifting capabilities of up to 4000 pounds and reaches of up to 236" (nearly 10 feet). They travel from one to $2.2 \mathrm{MPH}$ and at a $5 \%$ maximum grade under battery supplied electric power. They are capable of outdoor navigation on uneven terrain. The SGV travels on two driven and one steering wheel. The $4000 \mathrm{lb}$ lifting product has a width of 50 inches and a 72 inch vehicle length. It can turn around in an 8 foot wide aisle. Dispatch commands are sent to the vehicles over FM Radio Frequencies. The base station control system accepts load requests and dispatches them according to one of several schemes including FIFO, highest priority, or maximum queue time. Systems currently available do not meet all of the requirements described in this paper.

The vehicles navigate using dead reckoning and triangulation. In dead reckoning, heading and distance travelled are used to update the robot's understanding of its position in the environment. Due to the potential for wheel slip and other anomalies, triangulation is used to independently measure its position. Passive beacons, installed every 30 to 40 feet along the SGV's path, are made of bar-coded retro-reflective tape. A class I, low power laser system can identify the landmarks and measure the angle between itself and three beacons. Three angles are sufficient to compute the vehicle position. Obstacle detection and avoidance is accomplished with infra-red scanners that sweep up to 6 feet in front of the vehicle. Anything contacting the vehicle causes the emergency brakes to be applied. The supplier also offers a vision system option that allows the SGV to look for and find a load. 


\subsection{Conclusions}

Though remediation plans are not yet finalized, material handling requirements will most certainly increase dramatically as the retrieval, treatment, and shipping operations ramp up. At present, equipment utilization is not optimal and the situation could get much worse if operations are not brought on-line and under computer control and dispatch. This follows from the fact that it is more difficult to effectively track and optimize the utilization of a larger number of vehicles. ALARA concerns are partly responsible for underutilization of equipment and also are a major driver for the need for unmanned vehicles in this application.

A plan to develop Self Guided Vehicles to address these needs has been presented. The scope of the project is limited to the development of a single vehicle, centralized dispatch and tracking systems, and software simulations to demonstrate traffic management and operations management. It will result in a vehicle that can lift an 8000 pound payload, which is the maximum weight of a filled pallet or B-25 box. Applications that will be supported by the system include container movements both within and between facilities, loading of trucks and rail cars, and the consolidation, shipment picking and access of containers in waste storage areas.

The plan identifies three phases that will demonstrate progressively higher levels of automation. In Phase 1, a manually operated forklift will be modified to display dispatches from a central station, and a model based obstacle detection system will be built that can identify when a load being moved by the fork truck is about to crash into an obstacle. In Phase 2, a vehicle will be purchased and modified to support autonomous navigation and container grappling in structured environments and for a limited range of applications. In Phase 3, the vehicle will be improved to support operation outdoors and in less structured environments. The full complement of proposed applications will be tested, including the hand-off of waste containers at radiological zone boundaries. Further integration between dispatching, database and vehicular operations will be accomplished.

Radiation exposure to vehicle drivers from fixed contamination, and emissions from the waste, or from spills, will be eliminated using these driverless vehicles. The likelihood of collisions will be reduced by previewing the path to be taken with the container and checking for any possible collisions against an accurate, sensor-updated model of the environment. The vehicles will be able to consolidate container packing in storage areas automatically. They will also be able to access a specific drum in a close packed storage area, even if that means de-stacking and restacking multiple pallets.

FIFO shipments will be possible without having to constantly rearrange the containers. Multiple SGV's will be able to work in closer proximity with fewer traffic problems since their movement can be coordinated by a central control agent. Multiple shift operation seven days a week will be feasible. Images of the containers in the as-loaded configuration will be recorded to prove that the containers weren't damaged prior to shipment. Permanent records of the activity will be recorded and timestamped on unalterable media when appropriate. Paperwork will be reduced and operational predictability will improve. 
Other aspects of computer integrated remediation have also been presented. A holistic view of the operations can be developed that examines all operations that affect the current state of the remediation site. A network of the sequences and interdependencies between operations can then be abstracted and used to optimize the efficiency of the entire operation. The result is that operations (Container movements only in the SGV demo) will be dispatched based upon a prioritized list of scheduled and unscheduled (real time input) operations and access to up-to-date and accurate databases. The information required will include the deployment of equipment, 'product' (containers ready for shipment), 'work in progress' (material going through treatment processes), and 'raw material' (unretrieved waste).

The proposed SGV system will demonstrate some of the benefits that can be wrought by systems analysis and optimization of the site as if it were factory and then utilizing the many techniques that have jeen used to improve the efficiency of factory operations. The SGV demonstrations will provide impetus for further development of computerized systems to support this integration. Full integration of operations beyond container movement is beyond the immediate scope of the proposed SGV project.

Environmental remediation is not yet mature and uncertainty exists about the specific techniques for treatment, retrieval, storage, and disposal that are still being developed. However, this should not be used as an excuse for ad hoc solutions for the organization and control of the ultimate system of operations that will together bring the site to its goal state. Techniques used to integrate site operations can be developed independent of the nature of work being performed at the pickup/delivery stations.

The more mature field of manufacturing has developed multiple solutions to many of these systems control problems, in increasingly flexible environments such as job shops. Self Guided Vehicles already exist in the manufacturing world and have proven their value and reliability in many applications. While adaptation of SGV's to environmental remediation sites will require some additional engineering and development, the project as proposed is both feasible and relevant to the material handling applications that will be encountered at DOE remediation sites. The development and use of SGV's can further advance, on all fronts, the RTDP's mission to develop systems that are faster, safer, and more cost-effective, to the benefit of both Fernald and other DOE sites. 

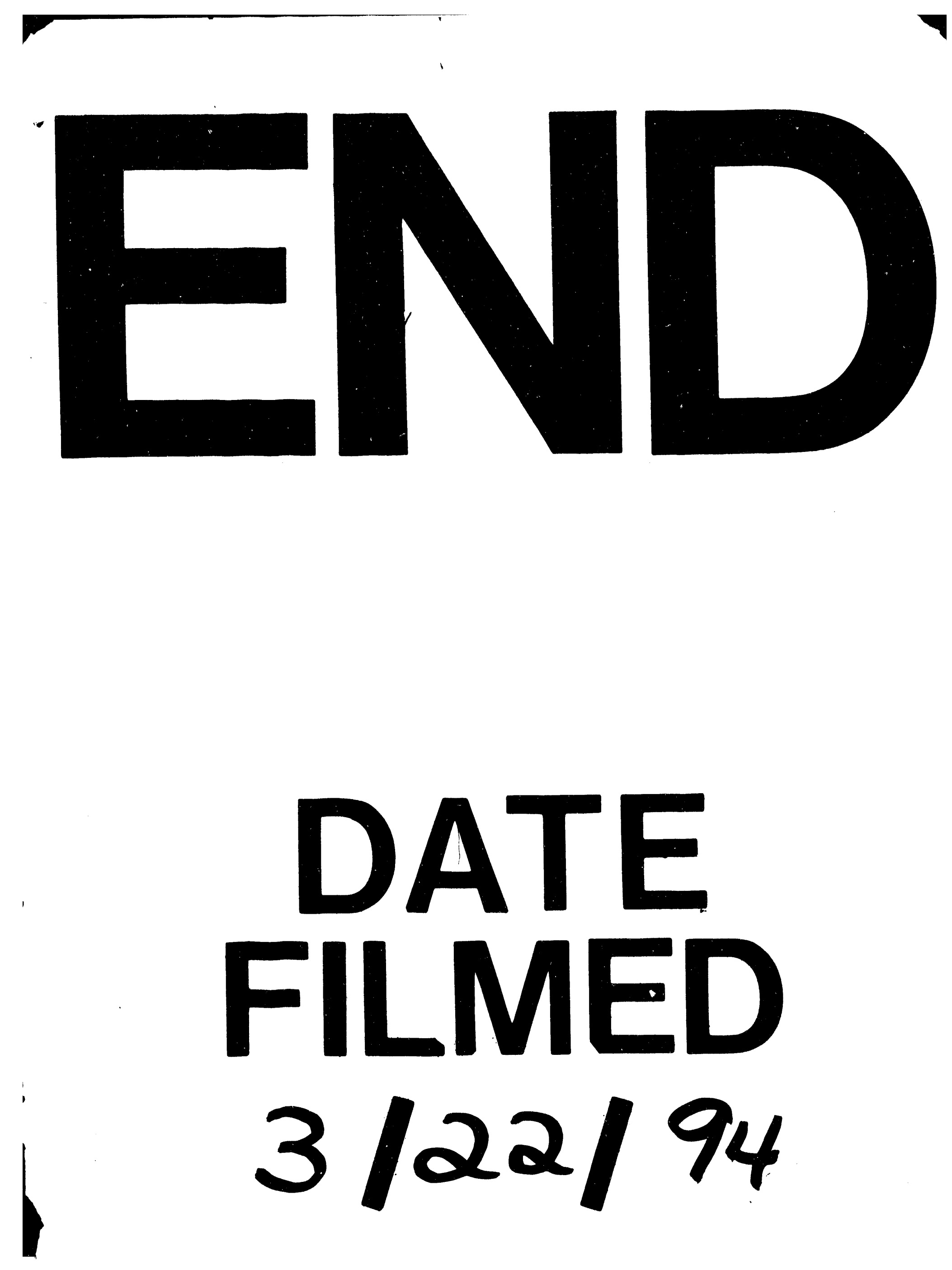